\title{
Environmental Control of Flowering and Growth of Lysimachia congestiflora Hemsl.
}

\author{
D. Zhang, A.M. Armitage, J.M. Affolter, and M.A. Dirr \\ Department of Horticulture, University of Georgia, Athens, GA 30602
}

Additional index words. dense-flowered loosestrife, photoperiod, temperature, irradiance

\begin{abstract}
Dense-flowered loosestrife is a quantitative long-day (LD) plant. Plants given a LD photoperiod (16 hours) flowered 21 and 34 days earlier than plants given 12- and 8hour photoperiods, respectively. Plants under LDs produced significantly more flowers than those under 8- and 12-hour photoperiods. Only 1 week of $L D$ was needed for $100 \%$ flowering; however, optimum flower count and size were produced with 3 weeks of LD. Plant dry weight did not differ significantly among treatments; however, LDs produced fewer but larger leaves, particularly those subtending the inflorescence. Total plant growth increased as temperature increased, but lower temperature (10C) decreased flower initiation and prevented flower development. High temperature (26C) reduced the persistence of open flowers. The optimum temperature for dense-flowered loosestrife growth was $\approx 20 \mathrm{C}$. Flowering was accelerated and dry weight production increased as irradiance levels increased from 100 to $300 \mu \mathrm{mol} \cdot \mathrm{m}^{-2} \cdot \mathrm{s}^{-1}$.
\end{abstract}

About 150 species included in Lysimachia (Primulaceae) are widely distributed in temperate and warm areas (Bailey et al., 1976), although only a few species are used as commercial ornamental plants (Armitage, 1989; Chatto, 1986). Recently, dense-flowered loosestrife has been grown commercially by American nurseries and is marketed as a bedding plant and hanging basket in the North and a half-hardy perennial in the South (Armitage, 1993). The species is native to central China and was first collected by Augustine Henry in the 1880s in the province of Hubei (Stafleu and Cowan, 1979), although it is unclear when and how the plant was introduced to American commerce. The scientific name refers to the terminal cluster of yellow flowers (Hemsley, 1890). Plants flower from April to October in zone 7 (U.S. Dept. of Agriculture, 1990) and are treated as an annual north of zone 9. The handsome, dull-green foliage and bright yellow flowers also lend potential for using the species in year-round production as a potted plant.

The phase change from vegetative to reproductive is characterized by induction of the apical meristem to initiate flower primordia instead of differentiating additional leaf primordia (Zevaart, 1963). The change not only is largely determined by genetics but also is controlled by environmental factors such as photoperiod, temperature, and irradiance (Evans, 1975). Cao et al. (1987) reported that the favored prefloral growth temperature ranges from 15 to $20 \mathrm{C}$ for the similar species

\footnotetext{
Received for publication 21 Mar. 1994. Accepted for publication 10 Sept. 1994. Thanks to American Floral Endowment and Gloeckner Foundation for supporting this work. The cost of publishing this paper was defrayed in part by the payment of page charges. Under postal regulations, this paper therefore must be hereby marked advertisement solely to indicate this fact.
}

Lysimachiafoenum-graecum Hance. The plant is also highly shade tolerant. Because no published information on environmental control of flowering and growth for dense-flowered loosestrife is available to our knowledge, we investigated the influence of photoperiod, irradiance, and temperature on flowering and growth of dense-flowered loosestrife.

\section{Materials and Methods}

Photoperiod. Well-rooted, three-node terminal cuttings of dense-flowered loosestrife were received in plugs from Ball Seed Company, Chicago, and transplanted to sunshine mix (LCl Fisons, Bellevue, Wash.) in 510-ml $(10 \mathrm{~cm})$, standard, rounded plastic containers on 10 Mar. 1993 and were fertilized with $\mathrm{N}$ at $50 \mathrm{ppm} 15 \mathrm{~N}-9.9 \mathrm{P}-14.1 \mathrm{~K}$. The 30 potted plants were placed in three environmental control growth chambers (model CMP3244; Conviron, Asheville, N.C.) at $20 \pm 2 \mathrm{C}$ with photoperiods of 8,12 , or $16 \mathrm{~h} /$ day (10 plants per treatment) with incandescent and fluorescent bulbs (50:50 input wattage). To ensure all plants in the three treatments received the same amount of light per day, we used $\approx 100,133.3$, and 200 $\mu \mathrm{mol} \cdot \mathrm{m}^{-2} \cdot \mathrm{s}^{-1}$ for the $16-, 12-$, and 8 -h photoperiods, respectively. The cumulative irradiance in each of the three chambers was the same, 5.8 $\pm 0.4 \mathrm{~mol} \cdot \mathrm{m}^{-2} \cdot \mathrm{day}^{-1}$. Plants were fertilized at every irrigation with $\mathrm{N}$ at $100 \mathrm{ppm}$ for the first 2 weeks and then $\mathrm{N}$ at $200 \mathrm{ppm}$, using $15 \mathrm{~N}-$ $9.9 \mathrm{P}-14.1 \mathrm{~K}$, to the end of the experiment. Time to visible flower bud was recorded; at anthesis, the number of flowers, leaf surface area, number of branches, length of the longest branch and internodes, and dry weight were measured. The total number of leaves were counted and the leaf area of leaves subtending the flowers (four leaves for each flower branch) was measured. The experiment was terminated after all plants under three treatments reached anthesis at 78 days.
Photoperiodic cycle. Terminal three-node cuttings from stock plants were rooted in medium containing 1 perlite : 2 vermiculite $(\mathrm{v} / \mathrm{v})$ in a mist house on 25 Nov. 1993 and held at 20 to $25 \mathrm{C}$. They were transplanted on $9 \mathrm{Dec}$. to the same-size containers with the same brand of medium used in the photoperiod experiment. Plants were maintained under greenhouse conditions in which day/night cycles were 20 to $25 \mathrm{C} / 15$ to $20 \mathrm{C}$, until plants were placed in environmental chambers on $16 \mathrm{Dec}$. Fifty plants were moved to the 16 -h photoperiod with irradiance of $100 \mu \mathrm{mol} \cdot \mathrm{m}^{-2} \cdot \mathrm{s}^{-1}$ [long day (LD)], and 10 plants were placed in the 8$\mathrm{h}$ photoperiod with irradiance of $200 \mu \mathrm{mol} \cdot \mathrm{m}^{-2} \cdot \mathrm{s}^{-1}$ [short day (SD)]. All other variables were similar to those in the chambers in the photoperiod experiment. Fertilizer (1.5N-9.9P$14.1 \mathrm{~K}$ ) was applied at each irrigation with $\mathrm{N}$ at $100 \mathrm{ppm}$. At the end of each week, 10 plants were transferred from the LD treatment to the SD chamber, and then the plants were exposed to continuous SD. The treatments were continuous SD, 1 week LD followed by SD, 2 weeks LD followed by SD, 3 weeks LD followed by SD, 4 weeks LD followed by SD, and continuous LD. Times to visible flower bud and anthesis were recorded. The number of flowering branches and flowers were counted when plants were harvested for shoot dry weight after all plants had reached anthesis or flowers had aborted at 65 days.

Temperature. Terminal three-node cuttings from stock plants were grown as in the photoperiodic cycle experiment and started on 8 May 1993. Well-rooted cuttings were transplanted as in the photoperiod experiment on 23 May and were grown for 8 days in the greenhouse where day/night cycles were $\approx 20$ to $25 \mathrm{C} / 15$ to $20 \mathrm{C}$. Plants were fertilized with $15 \mathrm{~N}-9.9 \mathrm{P}-14.1 \mathrm{~K}$ with $\mathrm{N}$ at $50 \mathrm{ppm}$. On 1 June, 30 plants (10 plants per treatment) were placed in the three growth chambers described in the photoperiod experiment. Photoperiod and irradiance in the chambers were $16 \mathrm{~h} /$ day and $94 \pm 3 \mathrm{~mol} \cdot \mathrm{m}^{-2} \cdot \mathrm{s}^{-1}$, respectively; temperature was held at 10,18 , and 26 , each $\pm 2 \mathrm{C}$. Fertilizer was applied at each irrigation with $\mathrm{N}$ at $100 \mathrm{ppm} \mathrm{N}$ until the end of the experiment. Time to visible flower bud, anthesis, and flower senescence were recorded. Plants were harvested when they reached anthesis or aborted flowers at 77 days after treatment initiation.

Irradiance. Terminal, three-node cuttings were prepared as described in the photoperiodic cycle experiment on 3 Aug. 1993. At the time plants were being transplanted, there were visible flower buds on each well-rooted cutting. Thirty plants ( 10 plants per treatment) were moved to the same growth chambers as the photoperiod experiment on 18 Aug. after the visible flower buds were pinched. Photoperiod and temperature in the chambers were $16 \mathrm{~h} /$ day and $20 \pm 2 \mathrm{C}$, respectively, with irradiance at $100 \pm 15,200 \pm 20$, and $300 \pm 51$ $\mu \mathrm{mol} \cdot \mathrm{m}^{-2} \cdot \mathrm{s}^{-1}$. Plants were fertilized to the end of the experiment (4 Nov.), as described in the photoperiodic cycle experiment. Days to visible flower were recorded, and shoot dry weight was measured after 78 days. A complete randomized design was used in all experiments. 
Plants were rotated within each chamber every other day to ensure complete randomization. All data were analyzed using an analysis of variance and Tukey's honestly significant difference test at $\alpha=0.05$.

\section{Results and Discussion}

Photoperiod. Dense-flowered loosestrife is a quantitative LD plant; thus, as days became progressively longer, time to visible bud became progressively shorter (Table 1). It is not possible to determine the critical photoperiod from the 4-h intervals we used; however, the delay from 12- to 8-h photoperiods was 13 days, compared to a delay of 21 days when the photoperiod was $12 \mathrm{~h}$ rather than $16 \mathrm{~h}$. This result suggests that daylengths $>12 \mathrm{~h}$ would be appropriate for commercial practice. SD also significantly reduced the number of flowers (Table 1), suggesting that fewer flowers were initiated or more flowers were aborted under 8 - and 12-h photoperiods. Because cumulative irradiance was about equal, regardless of photoperiodic treatment, it is logical that dry weights also were similar (Table 1).

Photoperiod had a strong influence on partitioning of vegetative and reproductive growth. Plants grown under $8 \mathrm{~h}$ light produced signifi-

Table 1. Influence of photoperiod on flowering and growth of dense-flowered loosestrife.

\begin{tabular}{|c|c|c|c|c|}
\hline \multirow[b]{2}{*}{ Characteristic } & \multicolumn{3}{|c|}{ Photoperiod (h/day) } & \multirow[b]{2}{*}{$\mathrm{HSD}_{0.0}$} \\
\hline & 8 & 12 & 16 & \\
\hline Days to visible flower buds & 61 & 48 & 27 & 3 \\
\hline Number of flowers & 21 & 87 & 416 & 46 \\
\hline Dry weight (g) & 9.4 & 8.7 & 9.3 & 2.2 \\
\hline Number of vegetative stems & 27 & 22 & 1 & 5 \\
\hline Number of flowering stems & 1 & 5 & 21 & 3 \\
\hline Number of nodes & 7 & 6 & 5 & 1 \\
\hline \multicolumn{5}{|l|}{ Length of longest } \\
\hline three internodes $(\mathrm{cm})$ & 5.4 & 6.1 & 9.0 & 1.4 \\
\hline \multicolumn{5}{|l|}{ Length of longest } \\
\hline three branches $(\mathrm{cm})$ & 22.7 & 21.5 & 22.9 & 3.3 \\
\hline Number of leaves & 440 & 316 & 174 & 84 \\
\hline Average leaf area $\left(\mathrm{cm}^{2}\right)$ & 3.5 & 4.6 & 6.4 & 0.6 \\
\hline \multicolumn{5}{|l|}{ Leaf area $\left(\mathrm{cm}^{2}\right)$ of } \\
\hline four leaves subtending flowers & 38.5 & 51.3 & 69.6 & 5.4 \\
\hline Total leaf area $\left(\mathrm{cm}^{2}\right)$ & 1528 & 1450 & 1116 & 419 \\
\hline
\end{tabular}

Table 2. Influence of long-day duration on flowering and growth of dense-flowered loosestrife.

\begin{tabular}{|c|c|c|c|c|c|c|c|}
\hline \multirow[b]{2}{*}{ Characteristic } & \multirow{2}{*}{$\begin{array}{c}\text { Continuous } \\
\text { short day }\end{array}$} & \multicolumn{4}{|c|}{ Weeks at long day ${ }^{2}$} & \multirow{2}{*}{$\begin{array}{c}\text { Continuous } \\
\text { long day }\end{array}$} & \multirow[b]{2}{*}{$\mathrm{HSD}_{0.05}$} \\
\hline & & 1 & 2 & 3 & 4 & & \\
\hline Days to visible flower buds & $---y$ & 29.1 & 28.8 & 29.1 & 28.9 & 29.0 & 0.5 \\
\hline Days to anthesis & $---y^{y}$ & 47.3 & 49.5 & 49.1 & 49.6 & 49.8 & 6.0 \\
\hline Number of flowering stems & 0.5 & 5.0 & 7.5 & 9.5 & 9.0 & 11.6 & 2.4 \\
\hline Number of flowers & 6 & 52 & 82 & 125 & 118 & 138 & 23 \\
\hline Dry weight (g) & 1.0 & 1.3 & 1.9 & 2.5 & 2.8 & 3.6 & 0.6 \\
\hline
\end{tabular}

${ }^{\mathrm{z}}$ After long day, short days were continued.

${ }^{y}$ Only $40 \%$ of the plants flowered by the end of the experiment.

Table 3. Effect of temperature on flowering and dry weight of dense-flowered loosestrife.

\begin{tabular}{lcccrr}
\hline $\begin{array}{l}\text { Temperature } \\
\left({ }^{\circ} \mathrm{C}\right)\end{array}$ & $\begin{array}{c}\text { Mean days to } \\
\text { visible flower bud }\end{array}$ & $\begin{array}{c}\text { Flower bud period } \\
\left(\text { days }^{z}\right)\end{array}$ & $\begin{array}{c}\text { Flowering period } \\
\left(\text { days }^{2}\right)\end{array}$ & $\begin{array}{c}\text { Senescence } \\
\left(\text { days }^{2}\right)\end{array}$ & $\begin{array}{c}\text { Dry wt } \\
(\mathrm{g})\end{array}$ \\
\hline 10 & $---\mathrm{y}$ & $--\mathrm{y}$ & --- & --- & 7.4 \\
18 & 29 & $21-56$ & $35-77$ & $--{ }^{\mathrm{x}}$ & 11.6 \\
26 & 21 & $14-42$ & $28-56$ & $35-63$ & 13.4 \\
$\mathrm{HSD}_{0.05}$ & 4 & --- & --- & --- & 1.7
\end{tabular}

${ }^{\mathrm{z}}$ Days from beginning of temperature treatment.

${ }^{y}$ Fewer than $40 \%$ of plants formed flower buds, and flowers totally aborted after 15 days; none reached anthesis.

${ }^{x}$ No flowers had senesced at the end of the experiment.
Photoperiodic cycle. Only $40 \%$ of the plants flowered by the end of the experiment when exposed to continuous SD, but $100 \%$ of the plants flowered when $\geq 1$ week LD was provided (data not included). There were no significant differences in time to visible flower buds or anthesis between LD durations (Table 2). However, plants exposed to $\geq 2$ week LD before SD produced significantly more flowering stems and flowers and weighed more than plants exposed to only 1 week LD (Table 2). Plants given continuous LD or 3 or 4 weeks LD had significantly more flowering stems and dry weight than those of the other treatments. These data suggest that only 1 week LD is necessary for complete flower initiation and development of dense-flowered loosestrife; however, for optimum production of flower stems and many flowers, $\geq 3$ weeks LD should be applied. Continuous LD resulted in the highest dry weight, flower count, and flowering stem count, but only dry weight was significantly higher for plants exposed to 3 or 4 weeks LD (Table 2).

Temperature. Temperature had a significant influence on flowering and growth of dense-flowered loosestrife (Table 3). After 40 days at $10 \mathrm{C}$, only $40 \%$ of the plants initiated visible flower buds and no flowers opened, suggesting that low temperature delays flower initiation and prevents subsequent flower development. At $26 \mathrm{C}$, the time to visible flower buds and flower development were accelerated relative to $18 \mathrm{C}$. Visible flower buds formed over 4 weeks, beginning 14 days from the initiation of the treatment until day 42 . Flowers opened $\approx 14$ days after flower buds were visible on days 14 to 42 , but they senesced in only 7 days (from day 35 to 63) (Table 3). Plants grown at $18 \mathrm{C}$ formed flower buds over a longer period (day 21 to 56 ) and reached anthesis 14 days later. No flowers senesced by the end of the experiment (day 77). The slower bud formation time and anthesis coupled with longer persistence of flowers at $18 \mathrm{C}$ resulted in plants of higher quality compared with plants grown at 26C. Plant dry weight significantly increased as temperature increased (Table 3 ), especially when $10 \mathrm{C}$ is compared to 18 and $26 \mathrm{C}$.

Irradiance. Flowering of plants grown under low-light conditions was significantly delayed relative to medium and high irradiance, but the delay was similar for the latter two (Table 4). This result means that denseflowered loosestrife does not require exceptionally high irradiance and may flower, albeit more slowly, under lower light. Dry weight was not significantly affected when irradiance was medium rather than high (Table 4), suggesting a degree of shade tolerance. Winter light may result in plants of unacceptable qual-

Table 4. Influence of irradiance on flowering time and dry weight of dense-flowered loosestrife.

\begin{tabular}{lcc}
\hline \hline $\begin{array}{l}\text { Irradiance } \\
\left(\mu \mathrm{mol} \cdot \mathrm{m}^{-2} \cdot \mathrm{s}^{-1}\right)\end{array}$ & $\begin{array}{c}\text { Days to visible } \\
\text { flower buds }\end{array}$ & $\begin{array}{c}\text { Dry wt } \\
(\mathrm{g})\end{array}$ \\
\hline $100($ low $)$ & 59 & 7.2 \\
200 (medium) & 43 & 14.0 \\
300 (high) & 40 & 12.7 \\
$\mathrm{HSD}_{0.05}$ & 9 & 2.4 \\
\hline
\end{tabular}




\section{Crop Production}

ity and supplemental lighting may be useful for flower acceleration and plant quality.

Dense-flowered loosestrife is a fastgrowing species with handsome yellow flowers and significant commercial potential as a hanging basket and potted plant. To produce the best quality plants, our data suggest that dense-flowered loosestrife should be grown under a photoperiod of $\geq 12 \mathrm{~h}$ for $\geq 3$ weeks at $\approx 20 \pm 2 \mathrm{C}$. Low-light areas $\left(<100 \mu \mathrm{mol} \cdot \mathrm{m}^{-2} \cdot \mathrm{s}^{-1}\right)$ should be avoided.

\section{Literature Cited}

Armitage, A.M. 1989. Herbaceous perennial plants. Varsity Press, Athens, Ga.

Armitage, A.M. 1993. Annuals: Grow the unusual. Greenhouse Grower 11(14):68-70.

Liberty Hyde Baily Hortorium. 1976. Hortus third. MacMillan, New York.

Cao, J., Z. Wu, Y. Bi, and X. Huang. 1987. Biological and cultivation ecological characteristics of cultivated Lysimachia foenum-graecum. Acta Ecologica Sinica 7(4):297-306.
Chatto, B. 1986. Lysimachia. Horticulture 64(7):22-23.

Evans, L.T. 1975. Daylength and the flowering of plants. W.A. Benjamin, Menlo, Calif.

Hemsley, W.B. 1890. Primulaceae. J. Linnean Soc. London XXVI:50.

Stafleu, F.A. and R.S. Cowan. 1979. Taxonomic literature (2nd ed.). The Hague Publishers, Utrecht, The Netherlands.

Zevaart, Jan A.D. 1963. Climatic control of reproductive development, p. 289-310. In: L.T.Evans (ed.). Environmental control of plant growth. Academic, Portland, Ore. 